\title{
The Study of Chinese Ancient Literature in the View of Culture
}

\author{
Tianhui Zhang ${ }^{1, a}$ \\ ${ }^{1}$ Chaoyang Teachers College, Chaoyang, Liaoning Province, China \\ a584347748@qq.com
}

Keywords: Culture, The angle of view, Chinese, Ancient literature

\begin{abstract}
Ancient Chinese literary classic cross-cultural translation, dissemination and research of countless cases show that the ancient Chinese literature helps to find local discourse and the discourse of interaction and humanistic value outside of isomorphism under the background of the cultural perspective. Cultural differences in context can lead to heterogeneous cultural misreading, pay attention to the ancient Chinese literature in the context of different cultures is accepted, be creative interpretation or misreading, help expand horizons in the dialogue, deepen the understanding of the problem in the collision and communication.
\end{abstract}

\section{Introduction}

At the beginning of the 20th century, Qichao, Liang predicted: "in this century's China, its waves wryly, colors, will be stronger in Europe of the last century. A brave man, please stand on the stage." In the past century, China was enveloped in the tide of world history and culture, both experienced a loss with shame, and feels the glory and dream. Meanwhile, bearing the national culture spirit and the artistic characteristics of Chinese ancient literature did not stop the pace of the spread abroad [1]. With the continuous improvement of China's comprehensive national power and influence, and respect for differences, diversity of multicultural coexistence concept approval by the people all over the world, the world demand for China's attention and significant changes have taken place, Chinese literature also shows unique brilliance.

\section{The research achievements of ancient Chinese literature}

In the past century, abroad sinologists in ancient Chinese literary field made remarkable achievements, a group to study Chinese literature for the academic expertise of Sinologist stand out, such as the United States Kerry, Hitouer, Frank Coltrane, British Arthur wily, France Donald holzman, Jie Drowned, Paul Jacobs, German Cubin, Matisuyaa, Tian zhong ten percent, South Korea's Li Xihao, Li Zhangyou, HongYin, Liu Shengjun, etc [1]. As different region in the context of "the other", the multi-dimensional research, broaden horizon and prudent super-knowledge, is not only the new add on Chinese ancient literature and rich, is also on Chinese literature status in the structure of world literature.

Foreign communication, influence and research of the ancient Chinese literature, in the past one hundred years has experienced from pay attention to the translation of "the classics" to literature comparison, the influence of the literary concept by comparing to the foothold in the context of literary texts and literature to and multi-level study process. In Europe and the United States, until the 1970 s most Sinologists inherit the missionary sinology research tradition and mainly affect the comparison [2]. After $70 \mathrm{~s}$, the British and American new criticism school of comparative literature, literary theory and the helm Rene Weller, ideas of literature research, under the influence of countries. Is the European and American scholars paying attention to the international horizon to discuss Chinese literature with western has the different cultural spirit, the positive interpretation of Chinese literature text, identification of Chinese cultural identity, in comparison to summarize characteristics of Chinese literature and the position in world literature pedigree, promote the spread of the ancient Chinese literature in the world [2]. "NORTON literature of ling", for example, is a classic literature corpus of authority in the western world, included in the book of the department of Ann compiled by Harvard University Yuen the NORTON anthology of Chinese literature: initial - 1911 ", by Yale 
university Maynard mike, editor of the NORTON masterpiece of world literature anthology, select translation and literary works in ancient China, with the introduction and related research articles, the study of Chinese literature in the western world is required reading. Professor at Yale university, east Asian Yu,Wenxi mark said: "previously, in comparative literature, both at Stanford, and Yale, choose classic is not Plato, Shakespeare, is now also becomes one of the main course of Chinese literature. So Chinese literature is from the nation but it is also from the world. From the study of Chinese literature, is an important period of development before and after 1970, academia by the previous traditional sinology into a new stage [2]. Now what Harvard teaching Yuen Ann (Stephen Owe) and others can be produced when a change of direction, they are based on the specific context of Chinese literature and into their academic background, on the research of Chinese literature."

In recent 10 years, the ancient Chinese literature research achievements abroad aroused the concern of the domestic academic circles and a batch of representative foreign research front of works have been published in domestic translation, only by American scholar Yuen Ann, for example, its important works "in the early tang poetry", "the glorious age of tang poetry", "China" medieval "end", "handy and Mengjiao's poem", "recall", "fan building", "Chinese literary theories: translation and criticism" and so on all have Chinese translation [1]. Developed because of the network and a large number of works translated and published in domestic and abroad today, a full review, review and summarize Chinese ancient literature spread abroad and the research has the basis and conditions. Actively carry out research in the field, not only can timely understanding of ancient Chinese literature overseas communication, influence and research results, understanding of the orientation of Chinese literature in the world, and it will promote discipline research deeply.

\section{The research of the development of the Chinese ancient runes}

The ancient Chinese literature has a long history with a glorious history, splendid achievements. A history of literature is a national rethinks, national literature classic is the image of national basic values and aesthetic reflection, is to identify the image symbol of their national identity. China ancient times literature major development can be summarized as:

In the early Qin period.Ancient myths and songs is the earliest oral literature creation, the pre-qin period, our country the first anthology of poetry in the book of songs. The book of songs started zero 5 first, as the source of China's realism literature, it has laid a solid foundation for the development of the later literature [3]. In the south of a new system of is produced with chu culture characteristics of poetry of chu, a great patriotic poet qu yuan, use this form to create the "nine songs" and "nine chapter". His representative works "li SAO" is the grand and magnificent long lyric poetry in the history of ancient literature, created the romantic tradition of poetry in China.

The spring and autumn period and the warring states period. The spring and autumn period and the warring states period, in an atmosphere of schools of thought contend, have their essays, which is suitable for quotations, the analects of Confucius "jar son" for dialogue, "chuang tzu" is good at debate, strongest and literariness, night out "xunzi" and "everything is done" has symposium. Of historical prose and reflect, including zuozhuan, as the chronological, " mandarin" and "ce" BieTi for the country, "ce" character is very good, words also spread a sharp and considerable literary value [4]. The qin dynasty, little literature Reese the suggestion by the guest book is only elegant prose.

The Han dynasty period.Han literature is of great vitality in the poems of folk songs, yue fu folk songs "feeling sad music, cause", strive to reflect the real life, to express the thoughts and feelings of the working people; It long dry elaborate narrative, language full of life breath, the sentence is given priority to with mixed dialect and wu, promoted the development of poetry art, "minister wife does for jiao the ancient poems is one of the most renowned [5]. Han dynasty literati woo poem also gradually mature, to the late eastern han dynasty in the lyrical poems nineteen ancient poems, is called "the crown of wu".

Through the early han dynasty prose is given priority to with political essays, the most famous theory of qin dynasty, the western han dynasty is a unified empire, cifu arises at the historic moment, to flourish, before and after emperor wudi produced MeiCheng "seven hair" sima xiangru "' fu" on Lin Fu etc when. Han prose achievement highest is sima qian's shiji, it not only created a new style of 
biographical history, and biography literature high-quality goods, skilled in narrative events and characters, language expressive, and also provides a hand of prose creation [4].

Wei-Jin Southern and Northern dynasties. Wei jin southern and northern dynasties is the era of literature to conscious, in poetry, prose, novel, prose, etc and ci has gratifying harvest. Han take years, produced by cao cao, xelloss,'s father and son as the core, such as maines "sussing out seven scholars" as the wings of his literary group, its poetry reflects the era of "generosity in gas" style; Then, ruan ji, records of kang, zuo si in wei-jin era, inherited the "take a character" fine tradition, tao yuanming is eastern central him great poet, his poems writing pastoral life and appeal, reclusion style natural dilution, is the cases of the pastoral poetry in China [5]. In xie lingyun and xie tiao are excellent landscape poets, and make free with a new system of seven-character express Baozhao cynical, from south to north into the northern is a master of the six dynasties poetry creation.

Tang dynasty period. In the tang dynasty, poetry has entered a golden age, early masters, sheng, middle and late periods, such as the star chi cloud chung, tang dynasty "tang four jie", larine, vibrated, their own features and later Chen zi-ang chutangsijie, on construction of character, force sweep JiLiang afterwinds, send for fresh, tang dynasty appeared two poetry schools, represented by wang wei, meng haoran landscape pastoral poetry, write hermit feelings, beautiful artistic conception; Represented by cross, ts 'en-ts 'an glorious pie, is good at depicting desolate magnificent frontier fortress scenery and arduous army life, magnificent style and artistic conception is large. Li bai and du fu successively rise, known as the Chinese poetry history and many historic "Gemini". Enthusiasm to sing praises of the motherland great rivers, li bai poetry, personal ideal performance of the sharp conflict with social reality, bold and unrestrained feelings, style and elegant; Du fu's poetry reflects the tang dynasty, a series of important events in turn tide, cut into all aspects of social life, therefore, has the reputation of "poetic history", his poems feelings deep within, depressed style [5]. Li Duzhi poetry, respectively by the romantic and realistic achievements, ZeBeiHouShi, become a shining example of a poem. After an lushan, headed by bai juyi, yuan zhen yuan and years, advocating the "new poems". They put forward "article to from time to time, song poems into matter and", created directly reflect the real life and the sufferings of the people of new poems. Bai juyi of the sentimental poetry "everlasting regret", "pipa", is also a popular masterpiece. Other famous poet, there is famous for its prosperity of han yu and meng jiao is known for it's bitter Yin jia dao, and the characteristic of liu yuxi, liu zongyuan, li ho, etc [6]. Tang is one of the most accomplished poet tu mu and li shangyin. Tu mu is longer than the four-line, wound spring don't borrow more and meditate on the poetry of history, style or embroidered brilliant, or handsome bright; Li shangyin oblique sink bo absolutely beautiful to poems on history and love DuShanShengChang, "acknowledged" the deep connotation, forever gaiety and metaphor, but some works become obscure.

There are two kinds of new style of the tang dynasty. Legendary characters vivid, bizarre story twists and turns, marked the maturity of ancient novel art; Ci from the earliest folk, bribing is growing in the tang dynasty literati, the first anthology of literati word "flowers" includes tang wen tingjun and west shu ci ci. Five generations down south where he li yu to words express the pain of national subjugation, more outstanding.

The Song dynasty period. To with the word of the song dynasty, tang said. Period poem, Ouyang, Xiu, Sheng, Zhang and others work more entertainment guest and linger. Zhongyan, Fan wrote state open, desolate style bold words. Always draw material from urban RenShi lower life, to write a city tour and acacia sorrow, a lot of slow word for developing language legacy, widely circulated in the citizens. Su shi break poem, word boundary, expand the word material, improve the state of words, expression of rich words, get rid of too much of temperament, opened has innovation significance of bold word to send [6]. In addition, the northern song dynasty Qin, He Zhu, Tingjian,Huang, Bangyan. Zhou, together create a variety of styles of ci poetry mastery of prosperity. Qingzhao, Li was the best female poet in ancient China; the word graceful and restrained is fresh, and the later work to write the feeling of life and the pain of home countries, especially moving. After getting change, when feeling hurt, gold and patriotism become major topics of ci creation, such as Yuangan,Zhang, Xiaoxiang, Zhang famous poets and the greatest patriotic poet Qiji,Xin of southern song dynasty, the ideology and spirit of song lyrics to reached an unprecedented height, in the aspect of art expression and form 
of the word has new breakthrough and creation. Simba send ci has a cat, Kezhuang, Liu and Chenweng Liu etc. The late southern song dynasty, the elegant ci claims, Shi Dazu, Guanguo, Gao, Wenying, Wu advocating the standard, pay attention to rules; Adherents of Zhangyan, Ci thorough, Yisun, Wang sad failure saying singing, song lyrics is the end of the finish.

Compared with tang poetry, song poetry has its own features. Has been famous poet Wang Yu Yang Yi said and "west" poets. Since Yaoju, Mei, Su Shunqin, Yangxiu,Oui, song poetry since the face, the biggest impact of the northern song dynasty poet sushi and huangtingjian, talked about his lyrical, freedom is bold and unrestrained; Tingjian, Huang, Jiangxi poetry, the style is thin hard gave birth to the new [6]. The southern song dynasty poet Yo,Lu, compose and Chengda, Fan, Yo, Lu are the most outstanding patriotic poet in song dynasty, poems left nearly all first, sing out of the golden era of zionist forte. In the late southern song dynasty has "always fine four spirit" and "river lake poetry". To the song dynasty, a national hero Tianxiang,Wen and adherents poets Yuanliang, Wang poem, sweep, added the last for the song dynasty poets with luster.

Yuan dynasty period.Yuan dynasty was the golden age of Chinese traditional opera literature. Works, the Dou yuan, Shifu Wang "western chamber", is bright is dazzing jewel in yuan drama. The story of pipa in the dynasties has well " [6]. A was popular tunes emerged in the yuan dynasty lyric poem cantata, namely description. Early snafu writers represented by works, and Zhiyuan, Ma works are easy, humorous and vigorous; On behalf of the writer is some late and georgie, style tend to be the standard Canon. Other important composers are YunShi, Guan, yanghao, Zhang and Huijing Chen, etc. The jin and yuan dynasties poetry is relatively inferior, YuanHaoWen is relatively outstanding poet.

In the Ming dynasty period. Urban economy highly developed in the Ming dynasty, to satisfy the needs of the citizens of a special style of popular literature such as novels, dramas and prosperity. Staple of Zhanghui novel, is the Ming guan in according to the folk story of finishing the reflection kingdoms. Shy naih-a "water swim the artistic reproduction of the song dynasty a mammoth peasant uprising. Appeared after the mid-Ming period, the novel creation, including such as chengen,Wu god evil spirit novel "journey to the west", is a romantic characteristics; The traditional novel "Jin ping mei" directly originated from the Ming dynasty social life, longer than mimic a world. Short stories of Ming dynasty is the main form of short, emphatically describe "citizen class of merchants, craftsmen, and the lives of prostitutes and mentality, including fengmeng long JiJi processing Shi,Yu say," the cautionary tong said "and" wake the constant talk ", LingMengChu compiled the cruces master, and the two carved spoils, called the "three words" "two pat" [7]. In terms of drama, Ming tang Xianzu legendary writer love opera the peony pavilion, reveals the theme of the feudal ethical code, embodies the spirit of The Times of individuality liberation the artistic imagination play magnificent, psychological description is exquisite, beautiful poems and moving, is a romantic masterpiece in the history of opera in China.

In the Qing dynasty period. Literary achievements in the qing dynasty when several novels, novels, Cao xueqin's "dream of red mansions" in Chinese ancient novels artistic peak; Wu ching-zu "the scholars", directed at examination system to select scholars for public office, literary history is one of the few irony masterpiece. Classical Chinese short stories have Pu, songling "strange stories, with numerous flower fox spirit's story, sing love, reflect the reality, attacked the malpractices and bizarre plot twists and turns, everyone wins [7]. Qing dynasty opera masterpiece when push hong sheng's the longevity palace and the direction of the peach blossom fan ", do the historical truth and artistic truth good unity.

After 1840s. After the opium war of 1840 China literature, shows the strong political nature and militancy. In poetry, the enlightenment thinkers gong mizzen first, and then, Wei Yuan, Lin zexu, Zhang Weibing also write butyl many works in color and historical significance. Before and after the reform, the reformist's representative of Liang qichao's ancient prose has broken the traditional pattern; broad, motivational, number is "new style". Xinhai revolution, southern clubs such as poet LiuYaZi work is permeated with the spirit of patriotism and democracy. The representative works of modern novels have the strange situation of twenty years have witnessed the officialdom in the sky, "resources cost" and "LaoCan travel notes", is called the four condemnation novels in the late qing 
dynasty [8]. The achievements of modern drama, mainly reflects in many local operas tend to mature, the widest influence of Beijing Opera, drama began to rise in our country, various drama groups in propaganda revolution, played an important role in enlightening. The outbreak of the "May 4th" new culture movement and literary revolution, marks the beginning of modern Chinese literature, literary history since then opened a new page.

\section{Summary}

All in all, only from the cultural background of China's unique, imagination, association, with the help of context, starting from China's unique cultural thinking, to understand and master the uniqueness of the ancient Chinese literature, to understand and master the means Chen Yunhan multi-valued, define elastic literary terms, concepts, and make it systematic; Only from China's unique cultural background, to understand and grasp the ancient Chinese literature in the empty spirit, fuzzy, simple words but deep meaning, and the corresponding expressions. In a word, only from China's unique cultural background grasp the whole Chinese ancient literature.

\section{References}

[1] Zh.H. Li, Style of Chinese Ancient Literature and Literary Spirit, Hubei People’s Pubilishing, 2012, pp.21-27.

[2] Y.K. Qi, The Ancient Chinese novel research, Fujiang People’s Publishing, 2005, pp.43-48.

[3] J.Zh. Lin, The cultural construction literary history, Peking University Press, 2009, pp.22-27

[4] L.F. Mao, Cultural Perspective classical poetics, China cultural press, 2012, pp.35-39

[5] T.M. Chu,New Classics Cultural, Bashu publishing, 2011, pp.63-67

[6] X.P.Yuan, National Cultural Study, Peking University Press, 2008, pp.47-51.

[7] Y.Sh. Wang and F.X. Tong, Ming and Qing dynasties literary history, Culture Press, 2013, pp.21-26.

[8] Ch.F. Chen, The development of modern Chinese literature, Shanghai Ancient Press, 2010, pp. 32-36. 